\title{
2021 TMS President Ellen Gerretar Aspiring Toward What Is Important
}

\section{Ellen Cerreta}

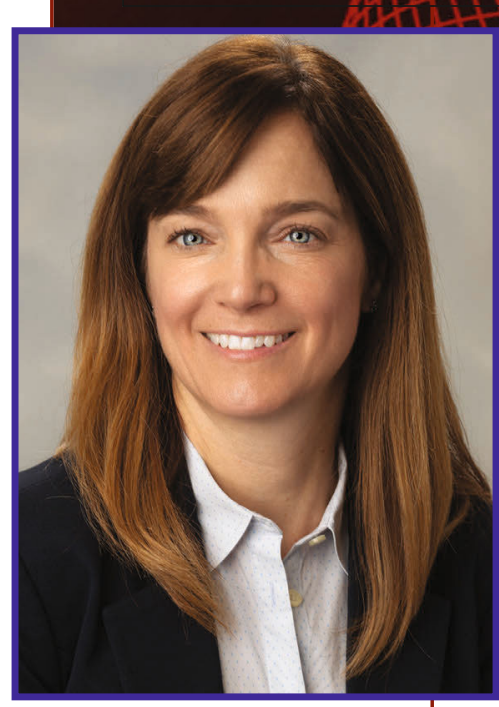

Ellen Cerreta

"What has

transpired since our

last in-person TMS

Annual Meeting in

2020 shouldn't be

allowed to change

what we are doing

as a Society for the

profession-even if

it is likely, perhaps

more than likely, to

change the how,

the implementation

of that vision."

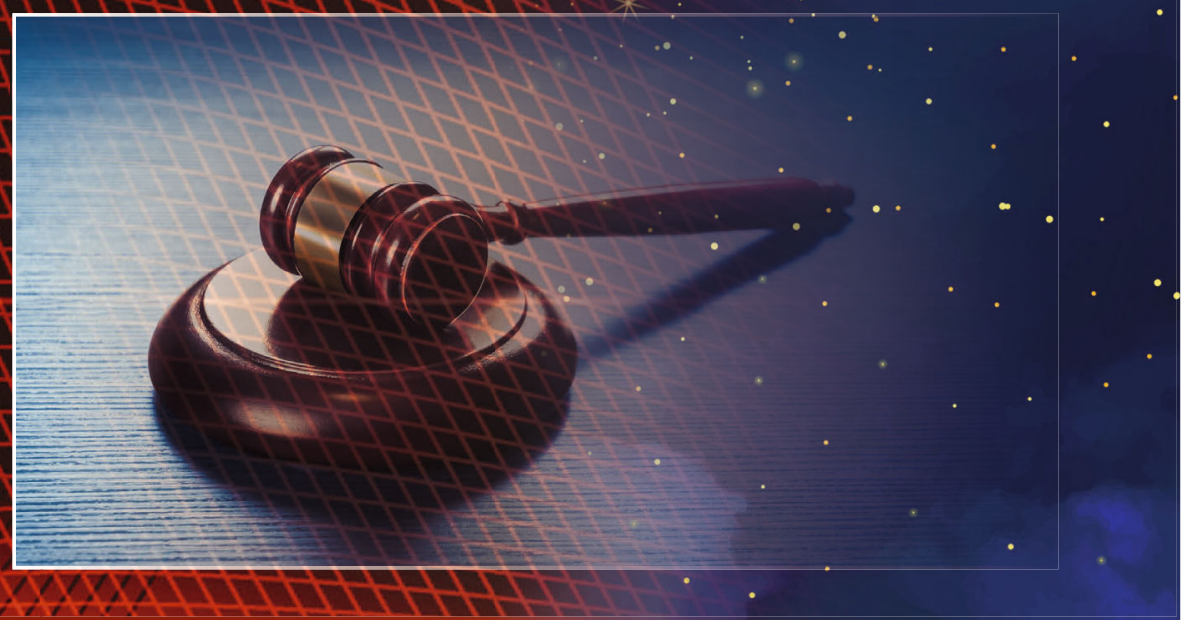

A year ago, when I became the Society's vice president, I would have told anyone who asked that I planned to lean on statements I submitted to the nominating committee for this role back in 2019. More recently, I started to think that was a bad idea, that perhaps statements I made during the nomination process have been overcome by the significant events of 2020, and that I should really rethink my approach. But as I thought more about that, I decided no. I did not want to do that. What has transpired since our last in-person TMS annual meeting in 2020 shouldn't be allowed to change what we are doing as a Society for the profession-even if it is likely, perhaps more than likely, to change the how, the implementation of that vision.

So, in these pages, I would like to share with all of you what I am hoping to lead as the TMS president. I will not get into the how, as I think space doesn't allow for that, and I think if this year has taught us anything, it is that how we do things is fairly dynamic and thus hard to pin down even a few weeks into the future, never mind months into the future.

Instead, I hope to provide a sense of what is important to me about TMS and how that has shaped my thoughts on the Society's current vision and strategyTMS Aspires-and how I believe that serves the profession. (Editor's note: see the sidebar, "TMS Aspires: The Society's Strategic Plan," for more information.)

I have been a TMS member since 1997. In the last 23 years, I have been an active TMS volunteer. As a student, I met my prospective postdoctoral mentor and was offered a position at Los Alamos National Laboratory at a TMS fall meeting in St. Louis. As an early career scientist, TMS helped me build strong international collaborations through its Young Leaders International Scholar Program in Japan. Finally, positions on the TMS Board of Directors enabled me to both witness and "try out" different leadership styles that have enhanced my career. As I reflect on what TMS has given to me, I know it is time to give back. And it is why I am absolutely honored to serve alongside the TMS staff and the Board of Directors to ensure, maintain, and grow TMS's high-value membership for materials professionals.

With that said, the part of this presidential role that I am most excited by is the ability to advance the 
"However, through

careful attention

to the strategy, I

believe we can

further enhance the

TMS experience,

inspire new

generations of

members, and

support our thought

leaders..." implementation of the vision and strategic plan for the Society: TMS Aspires. If you examine the TMS Aspires plan, you see it involves preserving core values of this member-driven society. These values include volunteer-driven programming, robust annual meetings, inclusive membership, and strong partnerships between basic and applied sciences. Simultaneously, this plan embraces change to further improve the TMS experience.

The core TMS values have made us a Society that offers benefits to its members like mentoring, peer review, high-quality content, and networking. However, through careful attention to the strategy, I believe we can further enhance the TMS experience, inspire new generations of members, and support our thought leaders as "they scope the future of materials engineering and technology." That, said more simply, is the future of our profession.

The TMS Aspires plan identifies three primary goals designed to make TMS the society of choice for all materials professionals. And as president, I want to leverage this strategy to examine new opportunities for our future meetingsparticularly MS\&T. As TMS aspires to be "the place where global MSE practitioners come together," the Society has deep resources to respond to societal issues of materials sustainability and professional grand challenges associated with big data and materials qualification. As part of the Board, I hope we can support and empower the members of committees like Integrated Computational Materials Engineering, Energy, Recycling \& Environmental Technologies, Additive Manufacturing, and Computational Materials - just to name a few-to continue to identify programming that addresses our profession's needs.

Most importantly, the strategic plan also emphasizes another core TMS value: "TMS aspires to be a highly inclusive society." To provide robust solutions to today's materials issues, we benefit from diverse backgrounds. This is particularly true in a professional society whose programming, products, and member

\section{TMS Aspires: The Society's Strategic Plan}

TMS Aspires, adopted in October 2018, is the strategic plan for The Minerals, Metals \& Materials Society. TMS Aspires comprises the following three goals, each of which is supported by a suite of objectives and tactics.

Goal 1. TMS aspires to be a highly inclusive Society where all materials students and professionals feel welcome and diversity is celebrated.

\section{Goal 2. TMS aspires to be the place where global materials practitioners come together and participate in vibrant annual meetings, specialty conferences, courses, student activities, and other events.}

\section{Goal 3. TMS aspires to be the Society that envisions, defines, and enables the future by gathering and empowering materials experts to scope the future of materials science, engineering, and technology.}


benefits frequently are driven by the ideas of its members. I am eager to champion the open dialogue required to do this well. I want to seek ways to enhance engagement of all members, which I think can, in part, be done through leveraging our division councils. Furthermore, TMS's portfolio of international activities, including the Young Leaders International Scholar Programs and co-programming at international meetings, are examples of how TMS's reach is becoming more global. I will be looking to involve more members in these international partnerships to ensure their long-term health.

Finally, one way in which to judge the health of the Society may be to examine the way it engages new members and volunteers. Material Advantage and the Young Leaders Programs have created tremendous opportunity and a tradition for transitions between student and professional membership. I believe our strategic plan directs us to examine these programs and ensure that we are providing valuable service to our student and early career members while also embracing inclusion.

So, I said that I wouldn't talk about the how, but as I conclude, I will say that implementing this plan is the hard work that I expect to engage in immediately. The success of this requires your support, and so it is a priority that we identify how to move forward, safely, while we stay true to this vision and in turn serve our profession.

\section{TMS Board of Directors}

Ellen Cerreta was officially installed as the 2021 TMS President at the TMS 2021 Virtual Annual Meeting \& Exhibition (TMS2021 Virtual) in March. The following individuals join her on the TMS Board of Directors to lead the Society in the coming year.

TMS President

Ellen Cerreta

Division Leader for Materials

Science and Technology,

Los Alamos National Laboratory

TMS Past President

Tom Battle

Extractive Metallurgy Consultant

TMS Vice President

Jud Ready

Deputy Director, Innovation

Initiatives,

Georgia Institute of Technology

TMS Financial Planning Officer Charles Ward

Chief, Manufacturing \& Industrial

Technologies Division,

Air Force Research Laboratory

Membership \& Student

Development Director/Chair

Alexis C. Lewis

Program Director,

National Science Foundation
Programming Director/Chair

Timothy Rupert

Associate Professor of Materials

Science and Engineering,

University of California, Irvine

Professional Development

Director/Chair

David L. Bourell

Temple Foundation Professor of

Mechanical Engineering,

The University of Texas at Austin

Content Development \&

Dissemination Director/Chair

Judith Schneider

Professor,

University of Alabama at Huntsville

Public \& Governmental

Affairs Director/Chair

Eric N. Brown

Division Leader, Explosive Science

and Shock Physics Division,

Los Alamos National Laboratory

Extraction \& Processing

Division Director/Chair

Christina Meskers
Functional Materials Division Director/Chair

Paul R. Ohodnicki

Associate Professor,

University of Pittsburgh

Light Metals Division

Director/Chair

Eric Nyberg

Technology Development

Manager,

Tungsten Heavy Powder \& Parts

Materials Processing \&

Manufacturing Division

Director/Chair

Mark R. Stoudt

Materials Research Engineer,

National Institute of Standards

and Technology

Structural Materials

Division Director/Chair

Daniel Miracle

Senior Scientist,

Air Force Research Laboratory

TMS Secretary/

Executive Director

James J. Robinson

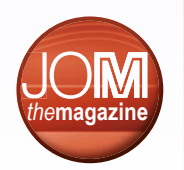

